\title{
Editorial
}

\section{The future of long-term care as a public health provision}

The spirit of the UK during the past 20 years has been one of self-centred drive towards independence' for individuals. This has been reflected in national politics and in policies which have weakened the infrastructure put together in the post-war years to support the needy by the strong. In keeping with this spirit more people chose to live alone. Bringing people together to provide for their shared needs is anathema to this philosophy.

Elderly people have been recipients of special residential care as an identifiable category for generations. 1 Latterly, Poor Law Workhouses have given way to residential homes, geriatric hospitals and mental hospitals (where at least half the beds have been used by elderly people since the 1950s). The great majority of this 'indoor' relief was provided in units directly managed by Local Authorities (Part III residential homes) and National Government (hospitals) up to the 1980s. Funding arrangements, clearly influenced by a philosophy that those in need should have their needs met and a choice over where and how, have sponsored a very large increase in alternatives within the 'independent' sector during the late 1980s. ${ }^{2}$ This has cost the Exchequer dearly in achieving most of its objectives. Yet it has reaped unforeseen 'side-effects'. Improved funding to 'indoor' relief has not been matched by easier availability of services to help people stay at home, so that the sensitive interface between tolerance within the community and institutionalized care has been shifted toward the latter. In the complex of a family's needs the balance between the wishes of patient (elder) and carer may have been tilted more towards the views of the more articulate carer, than the self-denying interests of the old person. Perhaps too many older people have been found a place in care, resolving tensions of the moment but leaving months or years of regret. ${ }^{3}$

Hospitals and health authorities have closed beds. Sometimes this has been because there appeared less demand for such facilities. Yet there is clear evidence that some authorities have removed long-term care from their list of available options despite the views of patients, carers and clinicians that it is a necessary part of a comprehensive service. ${ }^{4-6}$ Where it is absent there is encouragement to find a place in rest home or nursing home care before a patient (particularly one suffering from dementia) becomes 'too bad' to be accepted. If or when the patient does deteriorate and presents problems beyond the competence of a rest home or nursing home there may be no alternative but to retain him or her in this incompetent situation. S/he may begin a journey of nursing home transfers to new homes which have empty beds and will try to cope. For the carer who has struggled to manage at home until matters become desperate, there may be no relief, or worse: advice to place the loved one in an incompetent home, perhaps a distance away and into the hands of staff who have been ignorant of the struggle and a doctor who has no hand in it.

The provision of alternative 'homes' is not uniform in its distribution or costs. ${ }^{7}$ Inner cities, especially London, have generated few homes they would be too expensive to establish or run. 
Thus people have been 'bussed' to homes in other parts of the country to live out the last of their lives away from local accents, sights and gossip.

A good deal has been learned in these recent extraordinary years. Perhaps the most important revelation is that money, lots of it, can be released for the care of elderly people - given a framework that is acceptable to the government.

It has been confirmed that smaller units within localities have advantages over large, ill-sited, institutions. 8.9 Good quality care in smaller, properly-staffed units is probably more expensive than poorer quality care in large, ill-equipped units. $8-10$

Concern has been drawn to skills of care staff. There is a need for appropriately qualified staff from a range of disciplines to work in care homes: nurses, occupational therapists, speech therapists, physiotherapists, and others. Care assistants gain more from their work and give more to their 'clients' if they are trained and properly supported.

The medical contribution to care requires revision. Where 20 or more very dependent elderly people are gathered together, most suffering from multiple pathologies, there is a need for medical review on most days of the week with a formal discussion and revision of care plans weekly. The doctor should have special interest in the work and undertake appropriate training and study. This requirement is not reflected within present contractual arrangements for GPs. ${ }^{11}$ Other questions remain unresolved; partly because the appropriate questions have not been asked, sometimes because the very question has been thought 'out of order'.

Long-term hospital care has been compared with nursing home care in careful, sponsored studies. ${ }^{8,9}$ Yet the nursing homes have benefited from physical advantages of internal design and siting which could be available to long-term community hospitals and the relevance of management by consultant-led specialist staff has not been explored. The models of assessment have assumed that nursing homes/long-term care are closed/stand-alone entities and their best relationship with day care, support at home, other forms of long-stay care or acute hospital wards has not been considered. Whilst patients have done well in the NHS nursing homes most intensively researched, there are suggestions that some patients may be disadvantaged by removal from the direct care of a specialist team ${ }^{14}$ and in the real world of discharge to independent sector nursing homes, there is alarming evidence of precipitate decline and death. ${ }^{13}$ Whilst the virtues of "community care' are incanted daily, the preoccupation of those most actively involved at the front line of caring (families, clinicians, voluntary groups and fieldworkers) has remained the provision of a safe and suitable network of residential/nursing home/hospital beds. The essential characteristics of this network are that it is local and comprehensive. It is part of a system, no component of which stands alone as competent to meet the needs of the population of dependent elderly people. Thus care at home may only succeed if it knows of, and perhaps uses, respite care in a day centre or day hospital or in a rest home/hospital bed. Day care may fail if it lacks a relationship with the residential sector.

It is probable that levels of dependency/disturbance are increasing within all components of the 'residential' sector. ${ }^{14}$ Thus the availability of skills throughout the network is essential.

Long-term 'hospital care' should be available for those who require ongoing supervision from the full multidisciplinary specialist team: specialist doctor (consultant), nurses and therapists. This ensures that these individuals receive the best possible care and treatment. The facility within which this is given should be small ( 20 beds) and have homely advantages in keeping with the characteristics of the residents. In addition, these hospital units must link powerfully with other components of the care network: other residential units; hospitals/nursing homes/rest homes, offering liaison support and advice on the management of more vulnerable residents, acting as a training resource for staff. Day hospitals may be associated with long-term community hospital units and day centres with other forms of long-term care. ${ }^{15}$

Community care legislation which has very recently come into action seeks to ensure that the large amounts of money available for care of elderly people and others in need is spent most appropriately. The 'free-for-all' of the last half decade is being replaced by a managed system with professionals having control of the important interfaces. Best value for money should also facilitate best care for individuals. It is expected that there will be a reduction in the number of people institutionalised at public expense, but 
that more will be spent to help individuals and their families at home. It is expected that those who are placed 'in care' will be more disadvantaged by dependency and/or disturbed on average than those placed in the recent past. This will mean that skills in returning residents to the best possible health and maintaining them there will be at a premium. Staffing levels and skills mix will need to be increased and medical contributions improved. Average costs of care per individual must rise.

There may be a swing back toward more longterm hospital care - not in old-fashioned, ill-sited, outsized units, but in smaller, well-designed local units. This would foster the education and training of specialist staff whose skills should be disseminated to other components of the 'residential' care network rather than remain within the walls of the 'hospital'. Their activities will remain the proper province of the NHS and I see no sensible argument for rethinking their funding. ${ }^{16}$

Real progress requires that ideas generated by our recent experiences be formulated into new practices and that these practices be openly and systematically reviewed. Experience suggests that our evaluations are likely to be revealed as naive in themselves and never provide a final version of best practice. They will inform the process of search towards that mirage. Humble, earnest searching is good practice.

David Jolley, Consultant and Reader in Old Age Psychiatry, Healey House, Withington Hospital, Manchester M20 8LR, UK.

\section{References}

1 Towsend P. The last refuge. London: 1962. Routledge and Kegan Paul.

2 Social Security Committee of the House of Commons. Fourth Report - The financing of private residential and nursing home fees. London: HMSO, 1991.
3 Stout I, Wilkin D, Jolley D. Psychiatric morbidity amongst able residents of Part III homes. Int J Geriatr Psychiatr 1993 (in press).

4 Age Concern. Under sentence: continuing care units for older people within the NHS. London: Age Concern, 1990.

5 Millard P, Higgs $P$, Rochon P. Ageing: should it be left to chance? B Med J 1989; 298: 1020-21.

6 Benbow SM, Jolley DJ. A cause for concern: changing the fabric of psychogeriatric care. Psychiatr Bull 1992; 16: 567-69.

7 Larder D, Day P, Klein R. Institutional care for the elderly: the geographical distribution of the public/private mix in England. Bath Social Policy Papers, No. 10. Bath: University of Bath, 1986,

8 Bond J, Bond S, Donaldson C, Gregson B, Atkinson A. Evaluation of continuing care accommodation for elderly people. Health Care Research Unit Report, No. 38, Volumes 1-7. Newcastle upon Tyne: University of Newcastle upon Tyne, 1989.

9 Copeland JRM, Crosby C, Sixsmith AJ, Stilwell J. Three experimental homes for the elderly mentally ill. Institute of Human Ageing, University of Liverpool, 1990.

10 Beecham J, Cambridge P, Hallam A, Knapp P. The costs of domus care. International Journal of Geriatric Psychiatry. 1993 (in press).

11 The Royal College of Physicians. High quality long term care for elderly people. Guidelines and audit measures. London: The Royal College of Physicians, 1992.

12 Bowling A, Formby J, Grant K, Ebrahim S. A randomised controlled trial of nursing home and long stay geriatric ward care for elderly people. Age and Ageing 1991; 20: 316-24.

13 Roberts K. After hospital: a study of long term psychiatric patients in York. Department of Social Policy and Social Work, University of York, 1985.

14 Stern MC, Jagger C, Clarke M et al. Residential care for elderly people: a decade of change. $\mathrm{Br} \mathrm{Med} \mathrm{J}$ 1993; 306: 827-30.

15 Jolley D. Overview of a vision. Health Care of the Elderly 1993 (in press).

16 Kellett J. Long term care in the NHS: a vanishing prospect. Br Med J 1993; 306: 846-48. 